\title{
Waist to height ratio as a new marker of metabolic syndrome in type 2 diabetic patients.
}

Imen Horchani, Mehdi Oueslati, Meriem Ouerfelli, Ibtissem Oveslati, Karima Khiari, Néjib Ben Abdallah.

Department of Endocrinology, Charles Nicolle hospital. Tunis, Tunisia.

Metabolic syndrome is closely related to abdominal obesity. Classic anthropometric indices such as body mass index and waist circumference have been used for the screening of metabolic syndrome.

Recently, it has been reported that waist to height ratio is more closely associated with insulin resistance.

The aim of the present study was to assess the relationship between waist to height ratio and components of metabolic syndrome among type 2 diabetic patients.

A cross sectional analysis in 121 type 2 diabetic patients 56 women and 65 men.

口We measured anthropometric parameters (body weight, height, waist circumference (WC)) of each patient.

$\square$ Body mass index (BMI) was calculated as the body weight divided by the height squared.

$\square$ Waist to height ratio (WHR) was calculated as the waist circumference divided by height.

aFasting blood specimens were collected to measure fasting glucose, glycated hemoglobin (HbA1c), total cholesterol, triglycerides and HDL-cholesterol.

\section{DAnthropometric parameters}

\begin{tabular}{|c|c|c|c|}
\hline & Mean value & Ranges \\
\hline \multicolumn{2}{|c|}{ Body weight (kg) } & $73,72 \pm 16$ & $38-143$ \\
\hline \multicolumn{2}{|c|}{ BMI $\left(\mathrm{kg} / \mathrm{m}^{2}\right)$} & $27,43 \pm 5,57$ & $16,04-47,23$ \\
\hline \multirow{2}{*}{$\begin{array}{c}\text { Waist } \\
\text { circumference } \\
\text { (cm) }\end{array}$} & Male & $92,8 \pm 11,48$ & $64-110,5$ \\
\hline & Female & $98,84 \pm 11,89$ & $64-128,5$ \\
\hline \multirow[t]{2}{*}{ WHR } & Male & $0,55 \pm 0,07$ & $0,37-0,67$ \\
\hline & Female & $0,64 \pm 0,08$ & $0,38-0,84$ \\
\hline
\end{tabular}

\section{DPrevalence of overweight and obesity}

noverweight nobesity normal BMI

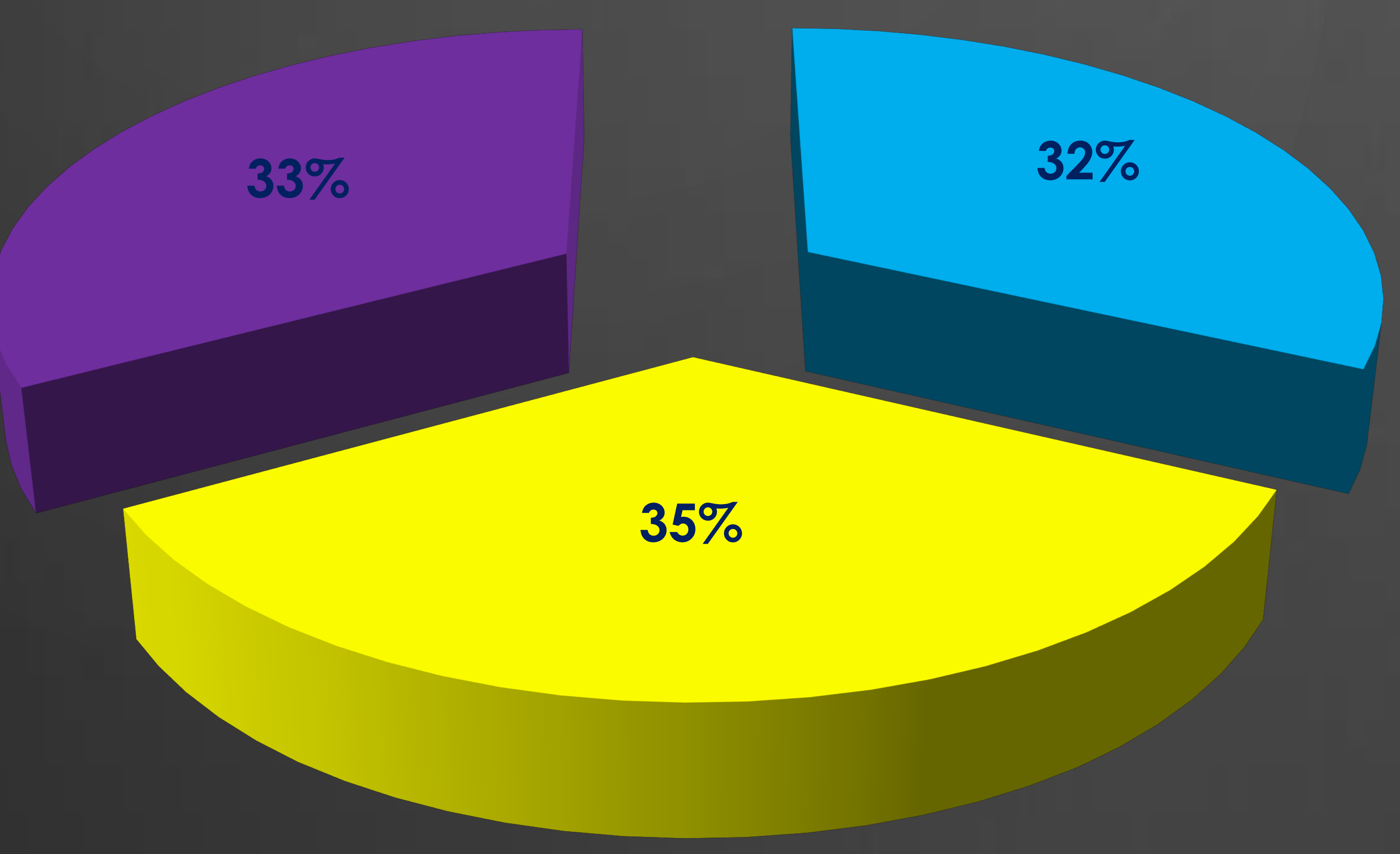

$\square$ Correlations between WHR, body weicht and B MI
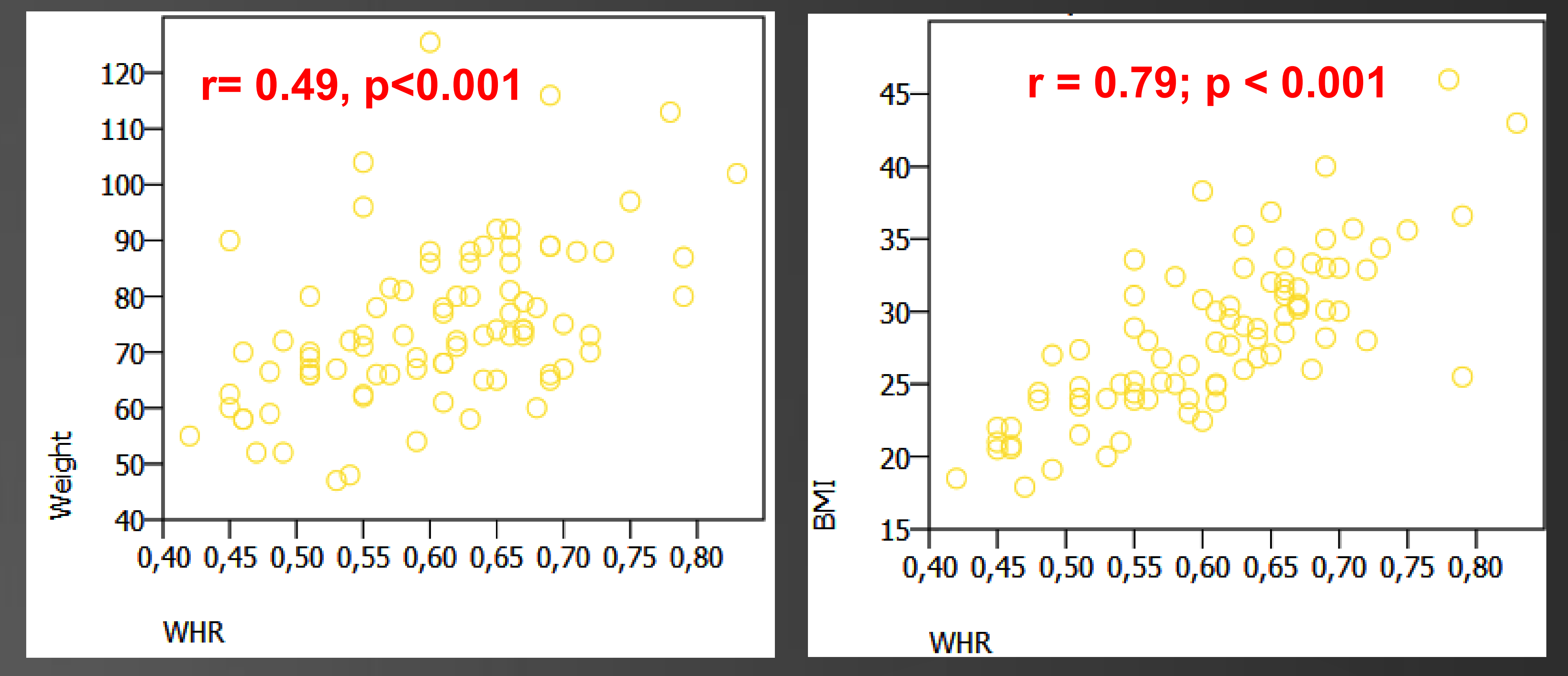

$\square$ Correlation between WHR and WC

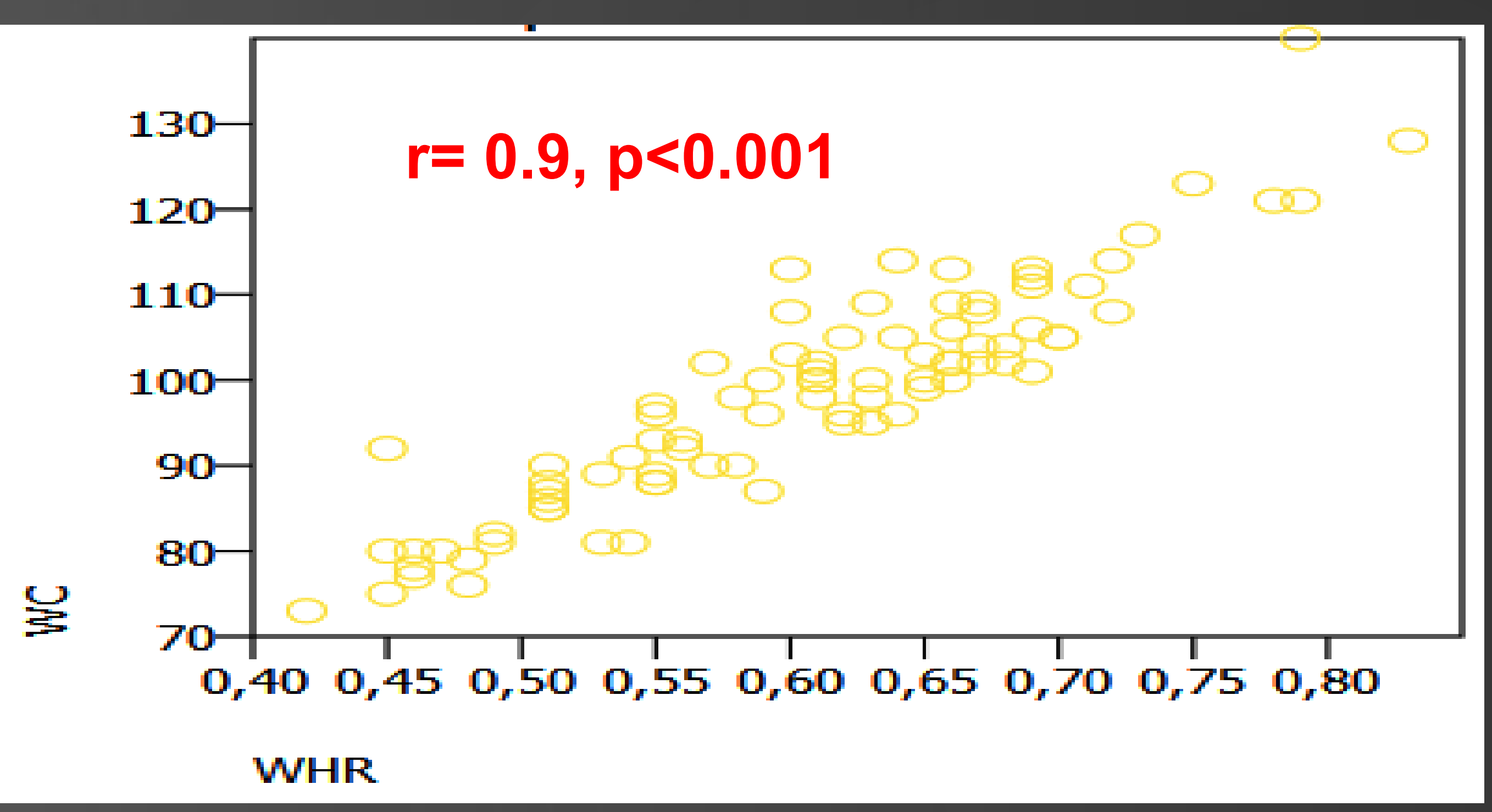

$\square$ Correlations between WHR and blood pressure

\begin{tabular}{|c|c|c|}
\hline & $r$ & $p$ \\
\hline Systolic blood pressure & 0.28 & 0.002 \\
\hline Diastolic blood pressure & 0.218 & 0.01 \\
\hline
\end{tabular}

$\square$ Correlations between WHR, lipid profile and glycemic control

\begin{tabular}{|l|c|c|}
\hline & $r$ & $p$ \\
\hline Fasting glucose & -0.01 & 0.8 \\
\hline HbA1c & -0.13 & 0.11 \\
\hline Total cholesterol & 0.3 & 0.001 \\
\hline Triglycerides & 0.314 & $<0.001$ \\
\hline HDLc & 0.02 & 0.8 \\
\hline LDLc & 0.02 & 0.8 \\
\hline
\end{tabular}

It has been demonstrated that waist-to-height ratio is a good predictor of metabolic syndrome. Regardless of sex and age, a cross-sectional, weighted sample estimated the risk factors as high if one's waist-to-height ratio was greater than 0.543 and only moderate between 0.498 and 0.543 (Kahn, 2003).

In our study, we found a positive correlations between waist to height ratio and three components of metabolic syndrome: waist circumference, arterial pressure and Triglycerides.

That 's why, waist to height ratio can be considered as a marker of insulin resistance and it may be a better indicator for screening overweight or obesity-related cardiovascular disease risk factors than the other indices 